This item was submitted to Loughborough's Research Repository by the author.

Items in Figshare are protected by copyright, with all rights reserved, unless otherwise indicated.

\title{
Mechanical characterization of individual Ni/Au coated microsize polymer particles
}

PLEASE CITE THE PUBLISHED VERSION

PUBLISHER

(c) American Institute of Physics

\section{VERSION}

VoR (Version of Record)

\section{LICENCE}

CC BY-NC-ND 4.0

\section{REPOSITORY RECORD}

Dou, Guangbin, David C. Whalley, and Changqing Liu. 2019. "Mechanical Characterization of Individual Ni/au Coated Microsize Polymer Particles". figshare. https://hdl.handle.net/2134/5276. 
This item was submitted to Loughborough's Institutional Repository (https://dspace.lboro.ac.uk/) by the author and is made available under the following Creative Commons Licence conditions.

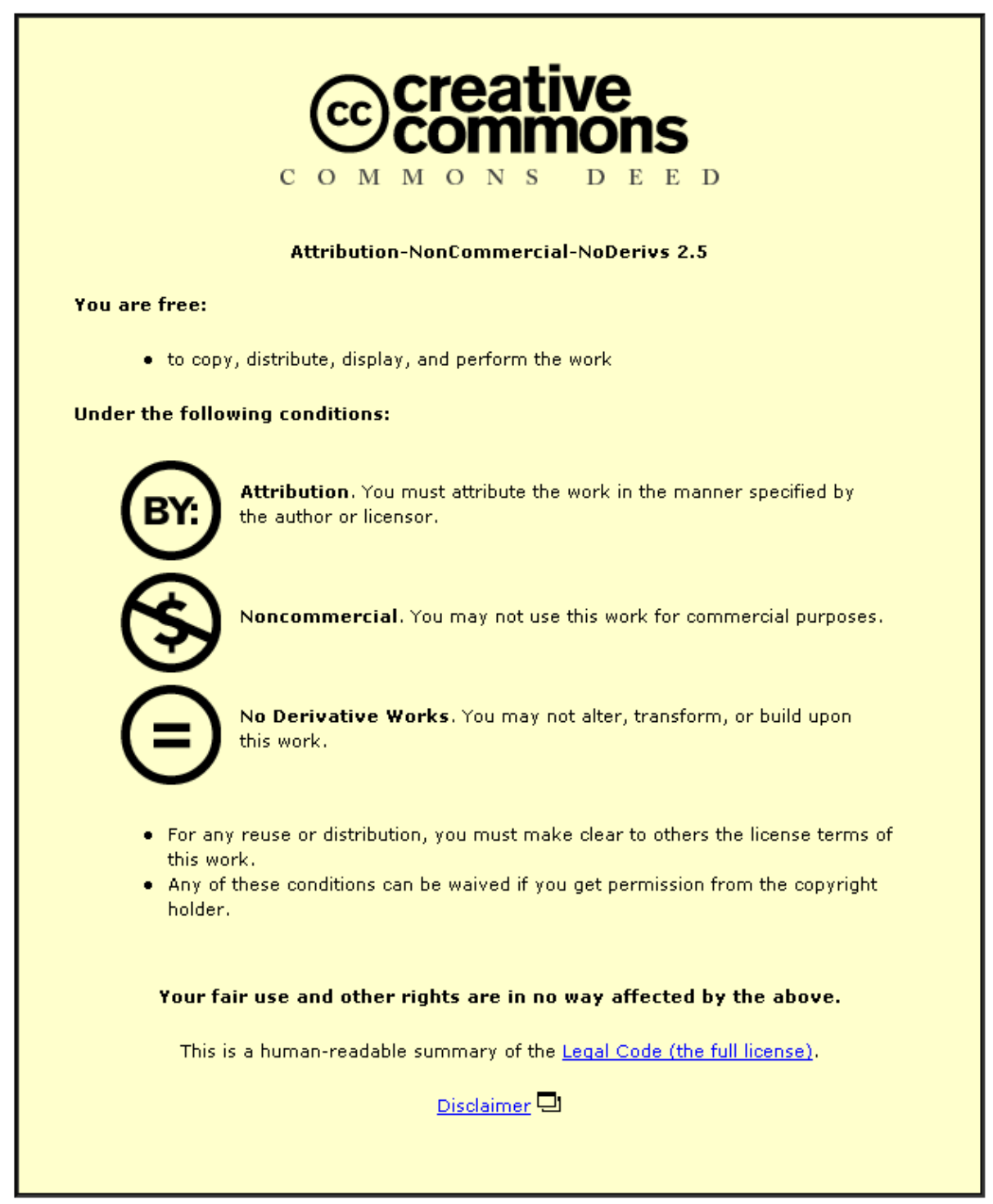

For the full text of this licence, please go to: http://creativecommons.org/licenses/by-nc-nd/2.5/ 


\title{
Mechanical characterization of individual $\mathrm{Ni} / \mathrm{Au}$ coated microsize polymer particles
}

\author{
Guangbin Dou, a) David C. Whalley, and Changqing Liu \\ Wolfson School of Mechanical and Manufacturing Engineering, Loughborough University, \\ Leicestershire LE11 3TU, United Kingdom
}

(Received 10 September 2007; accepted 16 February 2008; published online 14 March 2008)

\begin{abstract}
We report on a mechanical characterization technique for individual $\mathrm{Ni} / \mathrm{Au}$ coated microsize polymer particles. This technique allows a clearer understanding of the effects of load force and rate on the particle deformation. This has been achieved through measurements of the deformation against force using a specially configured nanoindenter machine, where the "indenters," instead of being pointed, had a flat tip of $20 \mu \mathrm{m}$ in diameter. The results show that the particle deformation process is nonlinear and that the force/deformation at which particle crushing occurs is affected by the load rate. The technique could be used to design/manufacture more effective conductive particles. (C) 2008 American Institute of Physics. [DOI: 10.1063/1.2898219]
\end{abstract}

In recent years, extensive interest has been focused on the development of lead free electronic packaging technologies due to legislation restricting the use of hazardous materials in a number of countries. The use of microsized metallic coated particles, mixed with a thermosetting adhesive resin to form an anisotropic conductive adhesive (ACA), is a conceptually simple method for achieving very high density interconnection of electronic components. For these reasons, they have become a critical technology in many applications, such as microelectronic packaging, flip chip bonding, and, particularly, flat panel display assembly. ${ }^{1-3}$ The deformation properties of the conductor particles are very important to achieving a reliable and low resistance connection and an improved understanding of their behavior will assist research to improve their performance and to establish the mechanisms that cause manufacturing yield and reliability problems. However, only limited research has been conducted into the deformation of these types of particle, especially for single particles. ${ }^{4,5}$ The reason for this is that the particles are too small to be deformed within normal material testing machines. The average mechanical properties of a large number of ACA particles have been previously measured by compressing them between flat plates. ${ }^{6,7}$ However, the maximum load per particle applied in those studies was insufficient to reach the crush point. Some experiments on individual ACA particles have been reported. ${ }^{4}$ However, only a modest level of deformation was achieved in these experiments due to the use of a large punch with a $100 \mu \mathrm{m}$ square flat tip, i.e., about 400 times the area of the particles tested and the tip and substrate were not sufficiently parallel. This resulted in the deformation being insufficient to allow the crushing behavior to be measured, which is a very important aspect of the conductor particle behavior. In this study, the load versus deformation behavior to a very high level of compression was measured, and the load rate effects on the deformation were analyzed.

\footnotetext{
${ }^{\text {a) }}$ Author to whom correspondence should be addressed. Electronic mail: gb.dou@lboro.ac.uk, g.duo@imperial.ac.uk. Tel.: +44(0)1509227661. Present address: Department of Electrical and Electronic Engineering, Imperial College London, South Kensington Campus, London SW7 2AZ, United Kingdom.
}

The particles used in this research were $5.75 \mu \mathrm{m}$ diameter microspheres of a cross-linked copolymer resin of divinyl-benzene (DVB) coated with $\mathrm{Ni}$ and Au layers. These particles are specifically designed for use in ACA applications and have a Ni layer of about $50 \mathrm{~nm}$ thick under a $\mathrm{Au}$ layer, less than $30 \mathrm{~nm}$. A NanoTest ${ }^{\mathrm{TM}}$ machine (schematically shown in Fig. 1) was adapted to deform the particles using a flat tipped punch instead of the diamond indenter normally used in nanohardness tests. ${ }^{8-10}$ The punch tip which was about $20 \mu \mathrm{m}$ in diameter was made from high speed steel (HSS). The tests involved force controlled deformation of the particles, where the force was increased linearly with time and the resulting deformation monitored. Glass microscope slides were used as base stages to support the deforming particles during these tests. Particles were generally found to have been crushed after the tests in the typical crush pattern shown in Fig. 2.

Figure 3(a) shows a typical deformation result for a particle, where the load rate was $1 \mathrm{mN} / \mathrm{s}$. The deformation of the particle showed a sudden increase in deformation after a deformation degree of just over $50 \%$ of the particle diameter

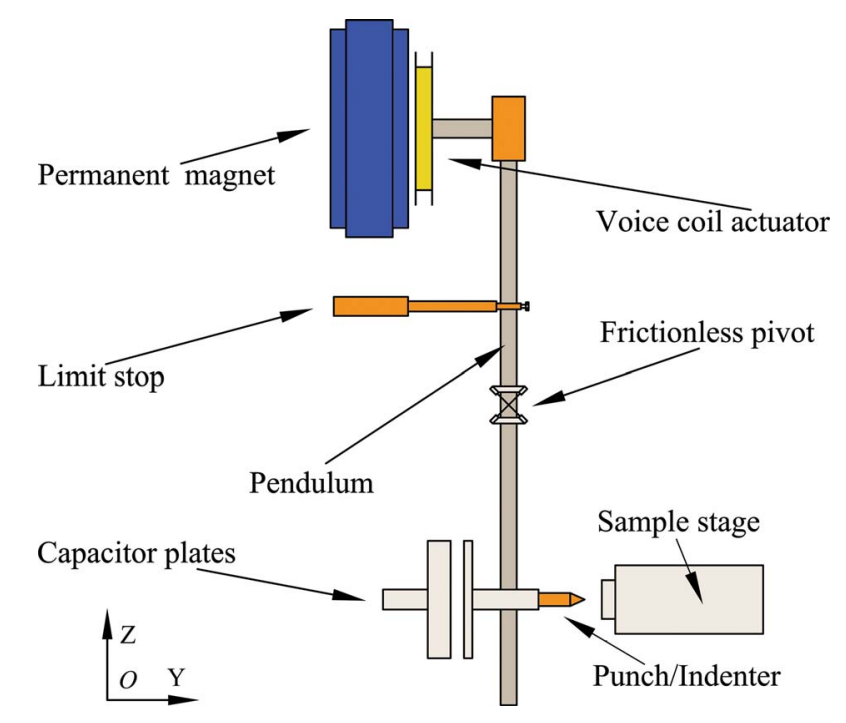

FIG. 1. (Color online) Schematic diagram of the nanoindenter. In the test, HSS punches tipped about $20 \mu \mathrm{m}$ in diameter were used. 


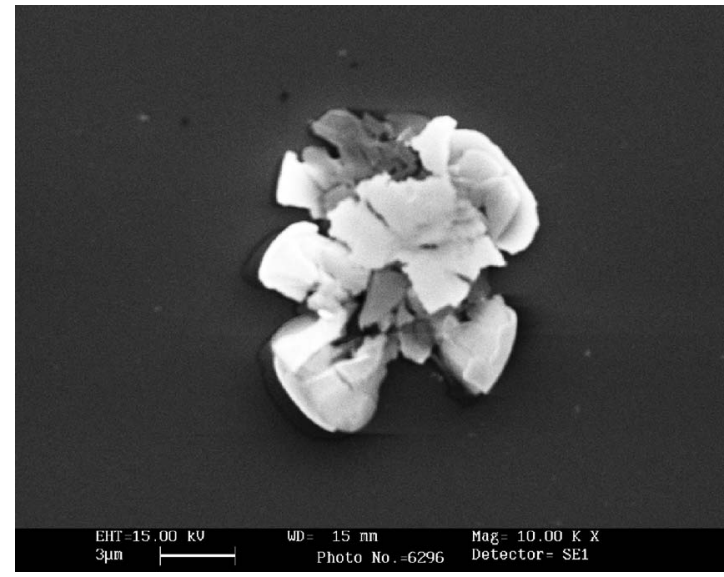

FIG. 2. Scanning electron microscopy of a typical crushed particle, electron high tension $(\mathrm{EHT})=15 \mathrm{kV}$, working distance $(\mathrm{WD})=3.0 \mathrm{~mm}$.

(here, deformation degree is the ratio of the deformed particle height to the undeformed diameter). This sudden increase in deformation is due to a catastrophic mechanical failure of the particle, as shown in Fig. 2, and the deformation at which this occurs is referred to as the crush point. The
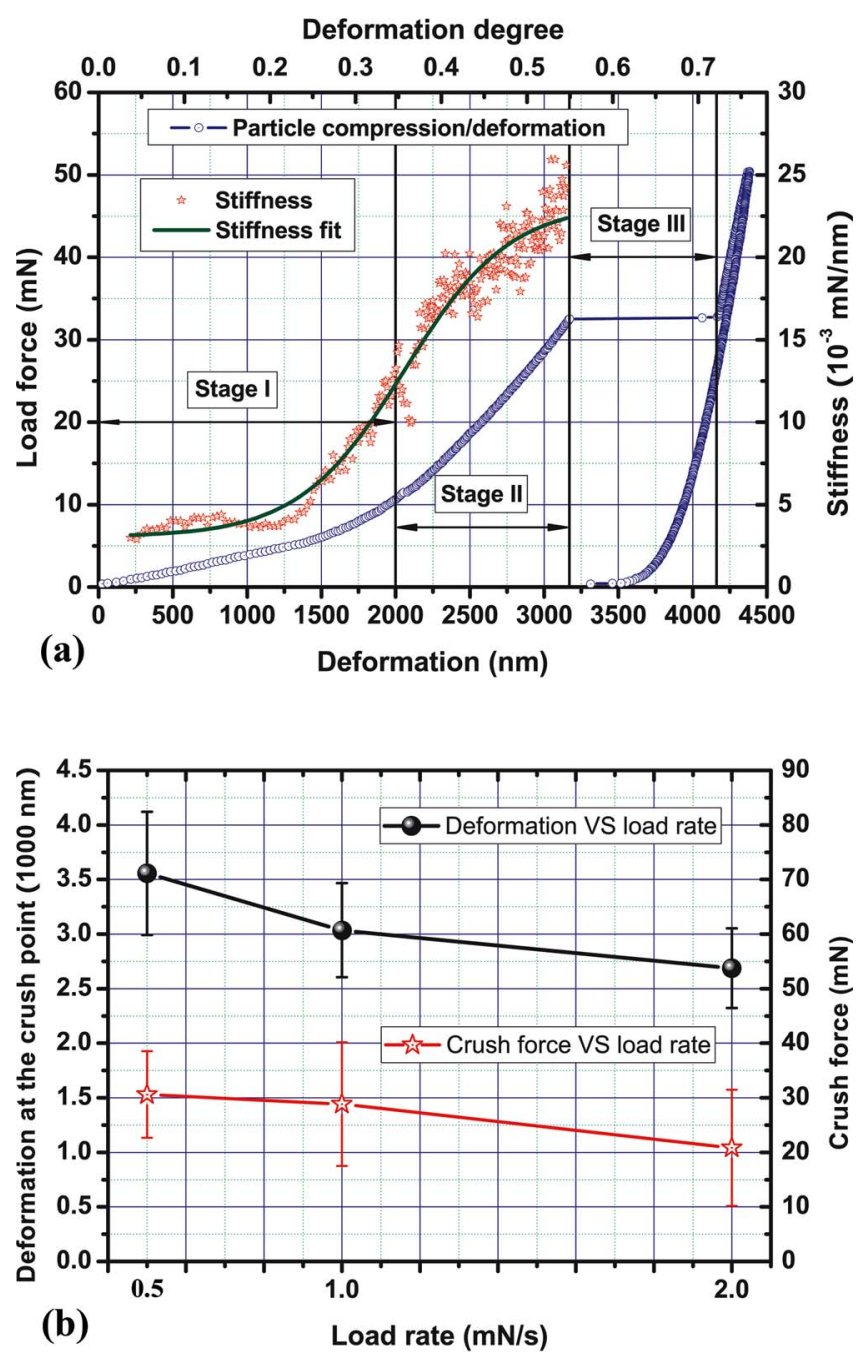

FIG. 3. (Color online) Results of mechanical deformation experiments. (a) Load and stiffness vs deformation. (b) Load rate effects on the particle crush point and crush force, the results are for the mean values for the deformation of eight to ten samples, with the error bars indicating one standard deviation

The results show that both the force at the crush point and
variation.
Downloaded 17 Mar 2008 to 131.231.136.78. Redistribution subject to AIP license or copyright; see http://apl.aip.org/apl/copyright.jsp slope of the load versus deformation curve indicates the particle stiffness. The particle stiffness was calculated as a moving average over seven data points, in order to reduce short term fluctuations due to the measurement noise, and is also shown in Fig. 3(a). It can be seen that the stiffness increased as the deformation increased, but that at high levels of deformation the rate of increase dropped, indicating that changes in the material behavior were starting to take place before crushing occurred. The results of the loading and unloading experiments for single ACA particles suggested that the effects of the test parameters on the particle deformation were complex. This complex behavior was believed to be caused by the size of the particles, the spherical geometry of the particles, and the materials of the particles. First, the particle size was small, and the surface roughness of the stage, the punch, and the particles may have affected the deformation process. Deformation of a sphere is complex, since the strain is localized in very small areas of the particle when the compression starts, and the materials near the contact point locally deform plastically. Finally, the presence of the metal layers also increases the complexity. During deformation, the material behavior is believed to include first the stretching of the metal layers, then the initiation and growing of cracks in the metal layer, which continue to grow until the initiation and growth of cracks in the polymer, resulting in the crushing of the particle at large deformations. These effects are a combination of geometrical nonlinearity (large displacement and contact) and material nonlinearity (plasticity, fracture, and hardening/softening properties of the materials during deformation). Furthermore, the polymer material of the particle core demonstrates viscoelastic behavior, ${ }^{1}$ so the behavior is strain rate dependent. The particle deformation as seen in Fig. 3(a) can be helpfully considered as occurring in four stages. Stage I: initially the deformation is approximately proportional to the load force applied until the deformation degree reaches approximately $25 \%$. Then, the particle stiffness began to rise well before a deformation of $2000 \mathrm{~nm}$ (35\% of the original particle size) because the initial deformation started from a point, and then the point increased into a circular area and grew larger and larger as the load force increased, but it was still small compared to the particle diameter. It can be concluded that the deformation was mainly concentrated in the contact area in this step. Stage II: this stage started at about 35\% particle deformation and continued until about 55\%. The stiffness increased significantly during this stage, since the deformed contact area became larger compared to the particle. Therefore, the shape of the deformed particle became more like a deformed cylinder, rather than a sphere. However, the rate of increase in stiffness was getting smaller before the particle was crushed. This is believed to be because small cracks initiated in the particle before crushing. Stage III: in this stage, the deformation rapidly increased from about $55 \%$ to around $72 \%$. The very low stiffness during this stage of deformation suggested that the particle was crushed during this step. Stage IV: in this stage, the load ramped up until the load reached the maximum force $(50 \mathrm{mN})$, followed by the unloading process. The particle had been crushed thoroughly, and the particle remains were very stiff and had almost no further plastic deformation as the unloading data shows.

The effects of varying the loading rate from 0.5 to $2 \mathrm{mN} / \mathrm{s}$ on particle crushing are shown in Fig. 3(b). The results show that both the force at the crush point and o AIP license or copyright; see http://apl.aip.org/apl/copyright.jsp 
the particle deformation before crushing were higher when the load rate was $0.5 \mathrm{mN} / \mathrm{s}$. At this loading rate, the particles deformed by about $4500 \mathrm{~nm}$, or around $80 \%$ of the original particle size, before crushing. However, the crush point deformation dropped to about $52 \%$ of the original particle size, about $3000 \mathrm{~nm}$, when the load rate was $1 \mathrm{mN} / \mathrm{s}$. Therefore, it can be concluded that the load rate affected the particle deformation process, delaying the crushing significantly at lower load rates. This is considered to be due to the viscoelastic properties of the polymer particles. The error bars in the figure suggested that the lower the load rate, the more variable the crush point. Figure 3(b) shows that the load force was about $31 \mathrm{mN}$ when the load rate was $0.5 \mathrm{mN} / \mathrm{s}$, but that it dropped a little, to less than $30 \mathrm{mN}$, when the load rate was $1 \mathrm{mN} / \mathrm{s}$. Therefore, there was no major difference in the crush load force between load rates of 0.5 and $1 \mathrm{mN} / \mathrm{s}$ if only the mean load force was considered. However, the crush load force was more variable at the higher load rate, as shown in Fig. 3(b). When the load rate was $2 \mathrm{mN} / \mathrm{s}$, the mean load force dropped to about $20 \mathrm{mN}$, which is a more significant drop than for the load rate of $1 \mathrm{mN} / \mathrm{s}$, and the variability was similar to that for the load rate of $1 \mathrm{mN} / \mathrm{s}$. It can be concluded that the high load rate, i.e., $2 \mathrm{mN} / \mathrm{s}$, caused the particles to be more easily broken, as the load force at the crush point was only about $20 \mathrm{mN}$, much smaller than the deformation in the load $0.5 \mathrm{mN} / \mathrm{s}$, where the crush force was about $30 \mathrm{mN}$.

This paper has demonstrated a technique for measuring the mechanical deformation properties of a single ACA particle. The typical load versus deformation behavior of individual ACA particles undergoing deformation was established. Four stages were identified in this process. The results show that the particle deformation is highly nonlinear, including the load and displacement at the crush point and the variability of the deformation behavior. They also show that at a low load rate, greater particle deformation before crushing can be obtained. This has implications for commercial assembly processes, where a high assembly rate is desired. It is believed that this sensitivity to load rate is due to the viscoelastic properties of the DVB polymer core within the particles. ${ }^{8-13}$ At higher load rates, this viscoelastic behavior will result in higher stresses in the polymer due to the reduced time available for the stresses to redistribute within the particle as it deforms.

We thank Dr. H. Kristiansen of Conpart AS, Norway, for sourcing the ACA particles for us.

${ }^{1}$ Y. Li, K. S. Moon, and C. P. Wong, Mater. Sci. 308, 5727 (2005).

${ }^{2}$ C. P. Wong, S. Luo, and Z. Zhang, Mater. Sci. 290, 5500 (2000).

${ }^{3}$ J. Liu, Conductive Adhesive for Electronics Packaging (Electrochemical, Port Erin, 1999), pp. 2-4.

${ }^{4}$ W. S. Kwon and K. W. Paik, IEEE Trans. Compon. Packag. Technol. 29, 528 (2006).

${ }^{5}$ G. B. Dou, D. C. Whalley, and C. Q. Liu, First Electronics Systemintegration Technology Conference, Dresden, German 2006 (unpublished).

${ }^{6}$ H. Kristiansen, U. Brudberg, and M. Gulliksen, Second IEEE International Symposium on Polymer Electronics Packaging, Gothenburg, Sweden, 1999 (unpublished).

${ }^{7}$ Y. Shen, Master of Engineering thesis, Chalmers University of Technology, 2001.

${ }^{8}$ A. Chakravartula and K. Komvopoulos, Appl. Phys. Lett. 88, 131901 (2006).

${ }^{9}$ D. Tranchida, S. Piccarolo, J. Loos, and A. Alexeev, Appl. Phys. Lett. 89, 171905 (2006)

${ }^{10}$ J. Zhou, K. Komvopoulos, and A. M. Minor, Appl. Phys. Lett. 88, 181908 (2006).

${ }^{11}$ D. J. Hourston and F. U. Schafer, High Perform. Polym. 8, 19 (1996).

${ }^{12}$ Z. Guo, H. Sautereau, and D. E. Kranbuehl, Polymer 46, 12452 (2005).

${ }^{13}$ I. M. Ward and D. W. Hadley, An Introduction to the Mechanical Properties of Solid Polymers (Wiley, West Sussex, UK, 1993), p. 45. 